\title{
Knowledge, attitude, practice, and post-infection effects regarding COVID-19, and vaccine acceptance among general people of North India - A multicentred cross-sectional study.
}

\author{
Sudhanshu Bansal ${ }^{1}$, Abhishek Kumar Gangwar ${ }^{1}$, Amit Sharma ${ }^{1}$, and Sourabh Kosey ${ }^{1}$ \\ ${ }^{1}$ ISF College of Pharmacy
}

June 5, 2021

\begin{abstract}
Purpose: This study aimed to assess COVID-19 awareness, attitude, practice, and post-infection effects, as well as vaccine acceptance, among general people in North India at the end of the first COVID-19 wave in India. Method: A cross-sectional, multicentred survey took place from 20 January to 28 February 2021 in Northern India, covering 8 states, including Haryana, Punjab, Himachal Pradesh, Uttar Pradesh, Uttarakhand, Jammu and Kashmir, Delhi, and Chandigarh to assess the KAP in the context of COVID-19. A validated questionnaire was distributed via social media (Instagram, WhatsApp), and responses were collected via a Google Form. Result: The total number of participants was n=813, out of which more than half of the responder were male $(54.2 \%)$. The majority of respondents belong to the age category 18 to 29 years $(66.9 \%)$ and $(85.8 \%)$ of respondents come from a nuclear family. Mean (percentage) scores for knowledge, attitude, and practice were $57.91 \%, 60.98 \%$, and $89.79 \%$ respectively. The vaccine acceptance in participants was quite high $(70.8 \%),(67.7 \%)$ have a positive belief in vaccine efficacy, and $(42.7 \%)$ of respondents were willing to take the vaccine at a health centre/clinic. Out of total participants (74.5\%) believe that vaccines can control the spread of COVID-19. The prevalence of post-infection effects was more in females with a mean percentage of 52.94, like (94.1\%) of females and (70.4\%) of males. Conclusion: Although the overall KAP regarding COVID-19 disease was average and balanced in some areas (69.56\% overall in all categories of KAP) in our participants. Our result finding shows that there are certain gaps in knowledge, attitude, and practice of participants which can be decreased by efficient and tailor-made health education initiatives. Due to these gaps, India is facing a second wave of COVID-19
\end{abstract}

\section{Hosted file}

Knowledge, attitude, practice, and post-infection effects regarding COVID-19, and vaccine acceptance am available at https://authorea.com/users/418096/articles/524969-knowledge-attitude-practiceand-post-infection-effects-regarding-covid-19-and-vaccine-acceptance-among-generalpeople-of-north-india-a-multicentred-cross-sectional-study

\section{Hosted file}

Tables.docx available at https://authorea.com/users/418096/articles/524969-knowledgeattitude-practice-and-post-infection-effects-regarding-covid-19-and-vaccine-acceptanceamong-general-people-of-north-india-a-multicentred-cross-sectional-study 